\title{
UMA ANÁLISE DO DIREITO À EDUCAÇÃO À LUZ DOS DIREITOS HUMANOS
}

\author{
Ana Cristyna M. Leite S. Bosco ${ }^{1}$ \\ Ana Beatriz Gonçalves Moreira Caser ${ }^{2}$
}

\section{RESUMO}

O estudo faz uma leitura dos Direitos Humanos à Educação em uma esfera internacional e interna; tratando seu contexto histórico, evolutivo e consequente reconhecimento da educação como Direito básico, indispensável e universal. Dessa forma, faz-se um estudo da educação, dos Direitos Humanos e de alguns documentos internacionais, bem como a influência na Constituição Federal de 1988. Baseado em pesquisas bibliográficas, método dedutivo e indutivo e análise de jurisprudências, o trabalho percorre o caminho para uma assimilação jurídica coerente. A pesquisa aborda os direitos humanos, a necessidade da família no processo educacional bem como a responsabilidade da evolução social.

Palavra-chave: Direitos Sociais. Direito Internacional. Escola. Universalidade.

\section{ANALYSIS OF RIGHTS TO EDUCATION IN THE LIGHT OF HUMAN RIGHTS}

\begin{abstract}
The present study do a reading of Human Rights to Education in an international and internal global sphere; treating in historical and evolutionary context and the consequent recognition of education as basic, indispensable and universal Law. Whith the ideas compacting, search for a study of education, Human Rights and some international documents, whit the influence in the Federal Constitution of 1988. With on bibliographical research and the deductive and inductive method, analysis of cases and jurisprudence. The study approaches the human rights, Family with your important role in learning process, and the responsibility of the state for evolution of society
\end{abstract}

Key-word: Social Right. International Law. School. Universality.

\section{INTRODUÇÃO}

A primeira parte do trabalho faz-se uma análise dos Direitos Humanos, da educação e a consequente proteção da pessoa humana. Destaca as gerações de Direitos Humanos, bem como a influência do iluminismo, na Declaração Universal de Direitos Humanos de 1948. Demonstra a educação e o Estado, no processo de transformação da sociedade e propõe que uma junção de normas e consequente surgimento de necessidades e reconhecimento desses

\footnotetext{
${ }^{1}$ Doutoranda em Direito pelo programa da UNESA- Universidade Estácio de Sá, Mestre em Direito Internacional pela UCB-Universidade Católica de Brasília, professora e pesquisadora do Uni-AnhangueraCentro Universitário de Goiás. Advogada. E-mail: anacristyna@gmail.com

${ }^{2}$ Doutoranda em Direito pelo programa da UNESA- Universidade Estácio de Sá, Mestre em Direito e Relações Internacionais pela PUC-GO, servidora pública do Poder judiciário Goiano e professora da PUC-GO. E-mail: abcaser.prof@gmail.com.
} 
direitos- diante da atual situação de globalização econômica e jurídica, bem como uma universalização de um sistema. Ainda, na mesma parte, a afirmação da educação como Direitos Humanos, por meio do artigo 26 da DUDH e art13, do Pacto de Direitos Internacional dos Direitos Econômicos, Sociais e Culturais.

Em um momento posterior, vem à tona a Constituição Federal de1988, como está postulado a educação, citando algumas decisões e exemplos do STF e a atual situação do país sob a égide constitucional. Ainda, busca expor o Plano Nacional de Educação e o Plano Nacional de Educação em Direitos Humanos e a Lei de Diretrizes e Bases. Assim, conclui-se o atual cenário do direito à Educação no Brasil.

Dessa forma, foram feitas pesquisas bibliográficas e utilizado os métodos dedutivo e indutivo para confecção e estudo da educação em âmbito jurídico-social.

\section{DIREITOS HUMANOS E A IDEIA DE PROTEÇÃO DO INDIVÍDUO}

A necessidade de transformação do mundo, está diretamente relacionado com a formação dos indivíduos e nesse sentido as práticas educativas, acontecem na família, no trabalho, no lazer e nas demais formas de convívio social, começa com o nascimento e termina apenas no momento da morte. A família constitui papel importante - já que adiciona amor e respeito pela função da escola. Assim, nada é mais importante que a educação. Para desenvolver a saúde ou qualquer pesquisa necessária- medicina preventiva, questões de longevidade - o caminho é a educação.

Nesse contexto global sobre educação, destaca-se o pensamento do Dr. Gikovate (2002, p. 61) que enfatiza a instituição de ensino, a transmissão de honestidade e firmeza de posição. Ainda, cita a dificuldade do processo educacional diante da globalização: “educar e formar filhos e alunos faz parte da nossa evolução, sobretudo considerando um mundo no qual mudanças de todos os tipos tem ocorrido com rapidez que temos presenciado"; ou seja, as grandes adversidades do mundo pós-moderno.

Evidencia-se, assim, a necessidade de um estudo mais aprofundado sobre o denominado direito básico: o direito a educação, tendo em vista a atual situação política e econômica do Brasil. Importante ressaltar que o Direito à educação está associado aos direitos humanos, bem como a diversidade cultural, pobreza, não se resumindo apenas no Direito de 
frequentar a escola. A educação deve ter qualidade e tem que ter capacidade de desenvolvimento, respondendo aos interesses da comunidade e de quem estuda; trata-se de um direito em sentido amplo.

Todas as previsões de crescimento e desenvolvimento de um país, estão pautadas na educação, porém, no auge do ano de 2018, ainda se percebe uma evolução insatisfatória sobre o tema. A sociedade ainda não consegue compreender que todas as mudanças; sejam elas econômicas, políticas, culturais e de consequente desenvolvimento, estão totalmente atreladas à necessidade de investimento à educação.

O questionamento dos Direitos Humanos à educação é referente a uma junção de normas e consequente surgimento de necessidades e reconhecimento desses direitos, com a atual situação de uma globalização econômica e jurídica, bem como uma universalização de um sistema. É importante considerar que o Direito à educação está vinculado com alguns aspectos culturais como: educação religiosa, a educação para paz e cooperação internacional entre as nações, de forma que exista respeito e tolerância. A sociedade internacional entende que esse direito é elementar, que tem início com a família e é complementado, obrigatório e gratuito na primeira fase até o ensino complementar (MONACO, 2008, p. 232).

Assim, torna-se necessário citar o antigo conflito direitos humanos $x$ direitos fundamentais, visto que a tentativa de enquadrar o Direito à Educação no módulo mais adequado. Em documentos internacionais, muitas vezes são usados Direitos Humanos e Direitos Fundamentais de forma distintas, como por exemplo da Carta das Nações Unidas. Há quem enquadre Direitos Humanos em uma esfera internacional e Direitos Fundamentais em uma esfera interna, porém, assim como afirma Mazzuoli (2016, p. 30), entende-se Direitos Humanos para uma proteção de ordem internacional e fundamentais quando a matriz protetiva se encontrar in foro doméstico. Entretanto, Direito à Educação será tratado como direitos humanos fundamentais no presente estudo.

Ao conceituar Direitos Humanos, Mazzuoli (2016, p. 25) afirma que este é "o conjunto de direitos e garantias dos ser humano que tem como finalidade o respeito e a sua dignidade, por meio de sua proteção das consequentes violações do poder estatal e a garantia de uma condição mínima de vida do indivíduo". Ainda, complementa que são Direitos que garantem às pessoas sujeitas à jurisdição de um Estado meios de 
reinvindicação de seus direitos, para além do plano interno, nas instancias internacionais de proteção.

Necessário se faz citar a compreensão da $\mathrm{ONU}^{3}$, que define os Direitos Humanos como garantias jurídicas universais que protegem indivíduos e grupos contra ações ou omissões dos governos que atentem contra a dignidade humana. Os direitos humanos são, pois, garantidos internacional e juridicamente protegidos, porque baseados em um sistema de valores comum, onde o centro é a dignidade do ser humano, obrigando os Estados e agentes estaduais e protegendo indivíduos e grupos- que não podem ser suprimidos nem negados e são iguais e interdependentes- isto é, nenhum deles é mais importante que os demais e o usufruto de qualquer um afeta o dos restantes. ${ }^{4}$

Direitos Humanos para alguns, surgem desde os primórdios - VII ${ }^{5}$ antes de Cristo para outros, tem surgimento com Jesus Cristo, com as ideias de respeito às minorias. No entanto, as ainda denominadas gerações de Direitos Humanos - tão criticada por muitos fundadas no lema da Revolução Francesa - liberdade, igualdade e fraternidade, resultaram no Direitos fundamentais, inspirações para as consequentes necessidades do mundo (MEDEIROS, 2011, p. 21). Vale destacar que o conflito sobre as gerações se relaciona com a nomenclatura, haja vista que estudiosos entendem que esses nomes podem levar a compreensão que uma geração substitui outra, o que na verdade seria uma análise equivocada, por isso a denominação dimensão satisfaz os autores contemporâneos.

A ideia que o Iluminismo influenciou não só o denominado século das luzes, como também, todas essas gerações ou dimensões as vezes é analisada de forma insatisfatória, haja vista a necessidade de fazer uma volta filosófica às influencias como as de Locke, Rousseau, Montesquieu. Entende-se que o século XVIII é marco importante para o movimento humanista, onde nem o Estado pode negar - já que os seus Direitos passam a ser protegidos pelas leis naturais e devem ser aplicados da mesma forma para todos. Surgem a Declaração da Virgínia (1776), a Declaração de Independência dos EUA (1776) e a Declaração francesa dos Direitos do Homem e do Cidadão (1789) bem como as demais Constituições que mantiveram os direitos daquele período (PES; REIS, 2011, p. 144).

\footnotetext{
${ }^{3}$ ONUBR. UNESCO - Organização das Nações Unidas para a Educação, a Ciência e a Cultura. Disponível em: $<$ https://nacoesunidas.org/agencia/unesco/>. Acesso em: 01.abr.2019.

${ }^{4}$ TAVARES, RAQUEL O que são os direitos humanos? Disponível em: <http://direitoshumanos.gddc.pt/ IPAG1.htm>. Acesso em: 02.out.2018.

${ }^{5}$ COMPARATO, Fábio Konder. A afirmação histórica dos direitos humanos. 10. ed. São Paulo: Saraiva, 2015.
} 
Buscando uma forma cronológica, no que tange as gerações ou dimensões necessário citar que: a $1^{\mathrm{a}}$ geração trata dos Direitos de Liberdade (Civis e políticos), $2^{\mathrm{a}}$ geração Direitos de Igualdade (econômicos, sociais e culturais), $3^{\text {a }}$ geração Direito da Fraternidade (desenvolvimento da paz, meio ambiente, comunicação e patrimônio da humanidade) e os Direitos de $4^{\mathrm{a}}$ Geração, Direitos de Solidariedade (Direito à democracia, à informação e pluralismo). Como destaca Weis (2012, p. 52):

Na realidade é preferível desde logo, destacar a matriz histórica dos direitos
humanos e atribuir-lhes, conforme o caso, uma alcunha que faça referência direta ao
movimento que os inspirou, ou ao conteúdo de suas prescrições. No lugar das
gerações, melhor seria falar em direitos humanos liberais ou direitos civis e políticos
e em direitos econômicos, sociais e culturais. À chamada terceira geração ainda não
ocorreu a consolidação de uma designação mais precisa, daí por que aqui se adota a
denominação " direitos humanos globais", havendo quem se refira a "direitos
humanos de solidariedade", uma vez que dizem respeito às condições de
sobrevivência de toda Humanidade e do planeta em si considerado, englobando a
manutenção da biodiversidade, o desenvolvimento sustentado, o controle da
temperatura global e da integridade da atmosfera, além dos consagrados direitos à
paz, à autodeterminação dos povos e etc.

Ressaltado por Trindade apud Weis (2012, p. 53), essas nomenclaturas surgem para facilitar a compreensão do tema, já que os direitos, diferentes dos indivíduos, não tem como gerar novos direitos como se verifica a sucessão geracional. Dessa forma, alguns autores compactuam com a nomenclatura, outros entendem que são feitas equivocada.

Tratar sobre a admissão do termo gerações de Direitos Humanos no STF é importante, mas também, vale o destaque sobre o tema 'Direito à Educação' o caso das vagas em creches públicas é, sem dúvida, o tema relativo à educação mais discutido no Supremo Tribunal Federal. Na realidade, trata-se de diversos casos, todos com o mesmo objeto, e o mesmo pedido: em virtude da falta de vagas, crianças de 0 a 6 anos ficam impossibilitadas de ter acesso às creches municipais, recorrendo (ou por meio dos pais, ou pela intervenção do Ministério Público) à tutela jurisdicional para garantir um direito previsto na Constituição Federal, como foi estudado por Lucas Aidar. ${ }^{6}$

\footnotetext{
${ }^{6}$ AIDAR, Lucas. Direito à educação no STF: conceitos, limites e possibilidades. Monografia apresentada à Escola de Formação da Sociedade Brasileira de Direito Público - SBDP, sob a orientação da Professora Patrícia Pessoa Valente. SÃO PAULO, 2011. Acesso em: 24.mai.2017. Disponível em: <http://www.sbdp.org.br/ arquivos/monografia/185_Lucas\%20Aidar.pdf> e <http://pne.mec.gov.br/>. Acesso em: 02.out.2018.
} 
Assim, compactuando com o estudo de Lucas e consequentemente o exemplo de Ministro Celso Mello citado por Mazzuoli (2016, p. 55), o Supremo Tribunal Federal ${ }^{7}$, no Brasil, reconhece as gerações em sua jurisprudência, como fez o referido Ministro em um caso sobre Direito à Educação, envolvendo uma criança de 5 anos e a necessidade de uma creche nos seguintes termos:

\footnotetext{
É preciso assinalar, neste ponto, por relevante, que o direito à educação- que representa prerrogativa constitucional deferida a todos (CF, art 205), notadamente às Crianças (CF, ART 208,IV e 227, caput) qualifica-se como um dos direitos sociais mais expressivos, subsumindo-se à noção dos direitos de segunda geração (ou dimensão) (RTJ164Q158-161).
}

Vale destacar sobre a consideração dos Direitos Humanos de $3^{\mathrm{a}}$ gerações como também, a verdadeira configuração do Direito à Educação como universal, o qual deveria ser garantido à todos, haja vista a existência de uma jurisprudência pacífica acerca do tema.

\subsection{Educação: necessidade do estado para transformação da sociedade}

O relatório Nacional sobre Direito Humano à Educação, que admite a educação como passível de proteção, considera o ser humano como indivíduo que vai além, buscando superar sua condição de existência no mundo - usa do seu trabalho, transforma a natureza, convive em sociedade, faz história; sendo a educação a arma fundamental para essas transformações, as quais admitem a educação em suas acepções (PLATAFORMA BRASILEIRA apud SACAVINO, 2006, p. 458).

Para dar continuidade à ideia da educação como Direitos Humanos, existe uma necessidade e entendimento não só da escola como também da educação em âmbito geral, para compressão e possível solução do problema social o qual se enfrenta atualmente. Confúcio, que viveu em tempo de caos e corrupção na China entendia que a educação consistia em comunicar a cada indivíduo, desde a infância, como deveriam ser os usos e costumes - de conhecimentos e artes, consagrados pela milenar tradição. A educação inicial advinha da família, onde o pai direcionava e ensinava o filho (PILATTI, 2016, p. 17).

A Educação, em linhas gerais, consiste na capacitação do ser humano em desenvolver um senso crítico e adquirir dignidade, uma visão geral global bem como o

\footnotetext{
${ }^{7}$ SUPREMO TRIBUnAL FEDERAL. A Constituição e o Supremo. Disponível em: <http://www.stf.jus.br/ portal/constituicao/artigobd.asp?item=\%201888> . Acesso em: 20.fev.2019.
} 
desenvolvimento de respeito ao próximo, a necessidade de uma base familiar capaz de contribuir com o desenvolvimento do respeito pelos direitos humanos e fundamentais, liberdades e garantias, e a manutenção da paz mundial.

Diante da sociedade atual tão cheia de problemas e necessidades, existe grande possibilidade da ausência de uma educação qualificadora deixar definitivamente comprometidos economicamente, se se analisar em contexto mundial. Ainda considerando uma situação de crise econômica severa, de acordo com uma análise pretérita de Buarque (2006, p. 36):

Continuamos na retaguarda do avanço técnico-científico e educacional. Nosso
tempo médio de escolaridade não passa de 6 anos, enquanto a Coréia e outros
países desenvolvidos 12 , em escolas de tempo integral e com ensino de alta
qualidade. Temos $10 \%$ de analfabetos entre a população adulta e quase metade dela
constituída de analfabetos funcionais- sabem ler, mas não entendem o que leem,
nem são capazes de fazer as operações matemáticas básicas. O quadro é ainda pior
quando se trata de analfabetismo digital

Impossível não questionar a estrutura político-social quando o tema é Direitos Humanos e Educação. A importância que a sociedade dá para educação em diferentes lugares e culturas está intrinsecamente ligada à evolução da referida sociedade. Conforme a citação, enquanto a Coréia o tempo de permanência na escola é de 12 anos, no Brasil apenas a metade, sem contar com as questões do ensino público, que são muitas vezes prejudicadas por vários fatores - professores não tem o mínimo de estrutura financeira para irem até as escolas exercerem suas funções. Não possuem estrutura financeira, não possuem investimento do Estado para trabalharem, formando um círculo vicioso de problemas dos professores, suas remunerações e as influencias geradas nos alunos.

Destaca-se também, a título de analise cultural e religiosa, a Declaração Islâmica Universal dos Direitos Humanos ao prescrever que "toda pessoa tem o direito de casar, fundar uma família e e educar seus filhos em conformidade com sua religião, sua tradição e cultura, art. XII; admitindo uma educação laica complementada pela educação religiosa (MONACO 2008, p. 236).

\subsubsection{Reconhecimento da educação como Direitos Humanos}


Juntamente com a história da evolução dos Direitos Humanos - onde alguns autores entendem que teve início 600 a. $C^{8}$ - com o surgimento do Budismo no Nepal - os denominados preceitos de igualdade, supremacia de direito e justiça constituem referências aos Direitos Humanos (PES; REIS, 2010, p. 143) e outros com as navegações. Em linhas gerais, todos compactuam com a ideia de que os Direitos Humanos vieram com os primórdios da humanidade.

Existem relatos que em 1921, a ONU reconheceu Direito à educação obrigatória, gratuita - relacionado ao combate ao trabalho infantil (SACAVINO, 2006, p. 458). Porém, não se pode deixar de citar a relação da educação no que e refere as questões sobre fome, miséria e direito à alimentação.

Importante salientar, que a II Guerra Mundial tem grande destaque para os Direitos Humanos, já que as grandes atrocidades resultaram em um documento - Declaração universal dos Direitos Humanos de 1948. Na época, a restauração do Direito Internacional era uma grande preocupação; tendo em vista que a sociedade estava dilacerada. O Brasil, em 1948, vivia sob a égide da Constituição de 1946- que formalizava a liberdade política e individualem prol de uma democracia. Os Direitos Humanos eram como hoje, apesar dos avanços, cheio de contradições, como bem citado no livro 60 anos da Declaração Universal dos Direitos Humanos- conquistas do Brasil.

Entende-se que o grande passo para o reconhecimento de proteção internacional da pessoa humana, no que também diz respeito à educação é a declaração de 48; que mesmo com todo o teor de proteção a pessoa, a Declaração Universal dos Direitos Humanos em seu artigo 26, trata especificamente sobre a educação:

1. Todo ser humano tem direito à instrução. A instrução será gratuita, pelo menos nos graus elementares e fundamentais. A instrução elementar será obrigatória. A instrução técnico-profissional será acessível a todos, bem como a instrução superior, está baseada no mérito.

2. A instrução será orientada no sentido do pleno desenvolvimento da personalidade humana e do fortalecimento do respeito pelos direitos do ser humano e pelas liberdades fundamentais. A instrução promoverá a compreensão, a tolerância e a amizade entre todas as nações e grupos raciais ou religiosos e coadjuvará as atividades das Nações Unidas em prol da manutenção da paz.

3. Os pais têm prioridade de direito na escolha do gênero de instrução que será ministrada a seus filhos.

\footnotetext{
${ }^{8}$ Comparato, Op. cit., nota 5
} 
Dessa forma, fica claro que cabe aos pais a instrução que será dada a seu filho, bem como o direcionamento para às escolas. Destacado por Mazzuoli (2016, p. 109-111) que o Pacto Internacional dos Direitos Econômicos, Sociais e Culturais deu juridicidade aos preceitos da DUDH de 48, com direitos mais amplos e bem elaborados.

No referente à educação - as normas de caráter programático, denominação usada para explicar o comprometimento do Estado para com a proteção desses direitos - é tratada de forma complementar, que existe o reconhecimento da família, da alimentação, do vestuário e da educação e esta deverá 'visar ao pleno desenvolvimento da personalidade humana e do sentido de sua dignidade e fortalecer o respeito aos direitos humanos e liberdades fundamentais', expresso no art.13 do referido pacto. Assim, com uma base jurídica internacional buscou-se demonstrar a importância do Direito à Educação para o desenvolvimento humano; partindo de uma visão global para uma visão interna, que será tratada a seguir.

Em conformidade com a necessidades do Pós Guerra, o Pacto surge com o intuito de manter o ideal do ser humano livre, no gozo das liberdades civis e políticas e liberto do temor e da miséria não pode ser realizado, a menos que se criem as condições que permitam a cada um gozar de seus direitos civis e políticos, assim como de seus direitos econômicos, sociais e culturais- conforme expresso no preambulo do referido Pacto. De forma bastante pontual, em 1966 “O Pacto Internacional sobre Direitos Econômicos, Sociais e Culturais”, trata em seu art. 13:

1. Os Estados Signatários do presente Pacto reconhecem o direito de toda pessoa à educação. Concordam que a educação deve ser orientada para o pleno desenvolvimento da personalidade humana e do sentido de sua dignidade, e deve fortalecer o respeito pelos direitos humanos e liberdades fundamentais. Concordam, ainda, que a educação deve capacitar todas as pessoas para participar efetivamente de uma sociedade livre, favorecer a compreensão, a tolerância e a amizade entre todas as nações e entre todos os grupos raciais, étnicos ou religiosos e promover as atividades das Nações Unidas em prol da manutenção da paz.

A importância da educação para a construção de uma personalidade e de um indivíduo diante de um cenário internacional, ficou explicitado no pacto. Assim, a educação primária a sociedade internacional percebe a necessidade de ser obrigatória à todas as pessoas, pública e gratuita, conforme art.13, n.2, a.

O documento expressa a real necessidade da garantia dos padrões mínimos de vida para todos, para além das adversidades econômicas, é no entanto, o centro da ideia de exigir a 
realização prática dos direitos econômicos, sociais e culturais. Segundo citação de Lima (2001, p. 97), bem como uma análise feita em sua obra do pensamento de Fraçoise Blanchard é destaque para análise das necessidades desses direitos sociais em tempos difíceis, já que especialmente quando o momento é complexo, o esforço para admiti-los são necessários para estabelecerem padrões de justiça social aceitáveis; esses direitos são os essenciais para a dignidade humana.

Tratam-se nesse momento, do Direito ao desenvolvimento. A Convenção Relativa à Luta contra a Discriminação no Campo do Ensino (UNESCO, 1960), também teve contribuição em questões pontuais acerca da discriminação no âmbito educacional -raça cor, religião entre outros tipos de discriminação- com o intuito que o indivíduo não desconsiderar ou mesmo dificultar a preservação do direito à educação.

Todos esses documentos - entre outros - contribuíram para a mudança social e consequente nova Constituição Federal, no final dos anos 80.

\section{ANÁLISE DO DIREITO À EDUCAÇÃO NA CONSTITUIÇÃO DE 1988}

Talvez o tema seja bem oportuno para se compreender a atual situação econômica e política do Brasil e consequentemente, a real situação educacional país. Com o intuito de situarmos no tempo e espaço, no ano 2000 deu início à um momento de incentivo e facilidades para a abertura de instituições de ensino superior privado. Obviamente, que em pleno ano de 2017 diversas instituições de ensino superior não se sustentaram econômica ou estruturalmente, o que levam à diversas discussões.

Assim, para a confecção do presente trabalho, procura-se a busca de uma breve análise do Direito à educação como Direitos Humanos, em especial, uma visão sobre o direito à educação nesses mais de 30 anos de Constituição Federal, sendo importante destacar que existe um problema relacionado à desigualdade, a pobreza e consequentemente a educação.

O processo de redemocratização que o Brasil passou no final dos anos 80, foi marco histórico constitucional, haja vista a transição do regime militar para o atual modelo democrático. O Brasil teve um avanço constitucional inigualável, e ordem de valores diversas das constituições anteriores: "profundamente impactada pela ênfase dada aos direitos humanos no âmbito internacional adotada pela ONU no ano de 1948, a Carta Magna 
Brasileira figura um generoso tributo axiológico aos direitos fundamentais do ser humano" (PIOVESAN; IKAWA; RAMIRES, 2010, p. 860).

A educação surge na Constituição de 1934, de forma inicial. O artigo 149 da Constituição de 1934, trata do tema:

A educação é direito de todos e deve ser ministrada pela família e pelos poderes públicos, cumprindo a estes proporcioná-la a brasileiros e a estrangeiros domiciliados no País, de modo que possibilite eficientes fatores da vida moral e econômica da Nação, e desenvolver num espírito brasileiro a consciência da solidariedade humana.

Em 1946, a educação também definida como direito de todos a qual deveria ser tratada em casa e na escola. Em 1969, em seu artigo 176, a Constituição Federal trata do tema como Direito de todos, a qual deve ser conduzida em casa e na escola, como na Constituição anterior, porém, inspirada no princípio da unidade nacional e nos ideais de liberdade e solidariedade humana.

Já em 1987, um manifesto que defendia à educação como um direito de todo cidadão, passando a ser uma obrigação do governo Federal em destinar mais de $13 \%$ e aos estados e municípios no mínimo $25 \%$ de sua receita tributária para manutenção e desenvolvimento do ensino público (PILLETI; PILLETI, 2016, p. 220).

Assim, todas essas constituições anteriores e especificamente este manifesto foram base para a Constituição de 88, que em seu art. 205 trata:

Art. 205. A educação, direito de todos e dever do Estado e da família, será promovida e incentivada com a colaboração da sociedade, visando ao pleno desenvolvimento da pessoa, seu preparo para o exercício da cidadania e sua qualificação para o trabalho.

Percebe-se que a família continua tendo um papel primordial para construção da educação, porém, surgem vários questionamentos sobre essa obrigação que passa a ser da sociedade, do estado e da família. Quem cumpre ou quem será punido se não cumprir? O Ministro Eros Grau relatou em RE 594.018 018 AgR (j. 23-6-2009, 2 ${ }^{\mathrm{a}}$ T, DJE de 7-8-2009) que “ A Educação é um Direito fundamental e indisponível dos indivíduos. É dever do Estado propiciar meios que viabilizem o seu exercício. Dever a ele imposto pelo preceito veiculado pelo artigo 205 da Constituição do Brasil. A Omissão da administração importa afronta à Constituição"

Alguns princípios importantes foram incluídos na CF/88, como no art. 206: 
Art. 206. O ensino será ministrado com base nos seguintes princípios:

I - igualdade de condições para o acesso e permanência na escola;

II - liberdade de aprender, ensinar, pesquisar e divulgar o pensamento, a arte e o saber;

III - pluralismo de ideias e de concepções pedagógicas, e coexistência de instituições públicas e privadas de ensino;

IV - gratuidade do ensino público em estabelecimentos oficiais;

V - valorização dos profissionais da educação escolar, garantidos, na forma da lei, planos de carreira, com ingresso exclusivamente por concurso público de provas e títulos, aos das redes públicas;(Redação dada pela Emenda Constitucional $n^{\circ} 53$, de 2006)

VI - gestão democrática do ensino público, na forma da lei;

VII - garantia de padrão de qualidade.

VIII - piso salarial profissional nacional para os profissionais da educação escolar pública, nos termos de lei federal. (Incluído pela Emenda Constitucional no 53, de 2006) Parágrafo único. A lei disporá sobre as categorias de trabalhadores considerados profissionais da educação básica e sobre a fixação de prazo para a elaboração ou adequação de seus planos de carreira, no âmbito da União, dos Estados, do Distrito Federal e dos Municípios (Incluído pela Emenda Constitucional $n^{\circ} 53$, de 2006).

Mesmo que a realidade atual na relação aluno $\mathrm{x}$ escola $\mathrm{x}$ professor não tenha modificado de forma tão acentuada- das constituições anteriores para a atual - percebe-se certa evolução no que tange as antigas constituições, já que tratou-se da permanência na escola, do pluralismo de ideias, da valorização do profissional e da gestão democrática (PILLETI; PILLETI, 2016, p. 221).

Quando se depara com a atual situação econômica, política, cultural do Brasil, alguns questionamentos vem à tona, bem como várias contradições as quais o estudo nos tendência a repensar. Existe no entanto, a identificação dos Direitos Humanos Fundamentais, extensivos às futuras gerações, sendo irrevogáveis e inalienáveis.

No Brasil, existe ainda, em pleno século XXI, necessidade de controlar a educação em uma Constituição, não só o direito a educação, mas o tempo de permanência na escola, as ideias e o reconhecimento do profissional da área de educação.

Mesmo sendo algo que não condiz com a situação do país, no art. 208, da Carta Magna, explicita a obrigatoriedade do Estado diante do direito à educação:

Art. 208. O dever do Estado com a educação será efetivado mediante a garantia de: I - ensino fundamental, obrigatório e gratuito, inclusive para os que a ele não tiveram acesso na idade própria; II - progressiva extensão da obrigatoriedade e gratuidade ao ensino médio;

I - ensino fundamental, obrigatório e gratuito, assegurada, inclusive, sua oferta gratuita para todos os que a ele não tiveram acesso na idade própria; (Redação dada pela Emenda Constitucional no 14, de 1996). 
O Estado possui deveres de fornecer, acompanhar a educação em todos os níveis, inclusive programas suplementares de materiais didáticos, transporte, alimentação e assistência à saúde.

\subsection{Plano nacional de educação}

Plano de Educação de 2014 - 2024 se divide em grupos que determinam diretrizes, metas e estratégias para a política educacional dos próximos dez anos, sendo que o primeiro são metas estruturantes para a garantia do direito a educação básica com qualidade, e o segundo grupo de metas diz respeito especificamente à redução das desigualdades e à valorização da diversidade, caminhos imprescindíveis para a equidade. O terceiro grupo de metas trata da valorização dos profissionais da educação, considerada estratégica para que as metas anteriores sejam atingidas, e o quarto grupo de metas refere-se ao ensino superior.

Assim, destaca as obrigações do governo diante da educação gratuita, assimilada com a necessidade da educação para a mudança de realidade do país e à uma busca de igualdade. O plano nacional também destaca os profissionais-pouco valorizados e a necessidade do ensino superior.

A Constituição Federal Brasileira e a Lei de Diretrizes e Bases da Educação Nacional LDB (Lei Federal n 9.394/1996) afirmam o exercício da cidadania como uma das finalidades da educação, ao estabelecer uma prática educativa, baseada na Liberdade, solidariedade e com a finalidade do pleno desenvolvimento do educando, seu preparo para o exercício da cidadania e sua qualificação para o trabalho. Ainda, necessário destacar que o Governo brasileiro tem o compromisso maior de promover uma educação de qualidade para todos, entendida como direito humano essencial. Assim, a universalização do ensino fundamental, a ampliação da educação infantil, do ensino médio, da educação superior e a melhoria da qualidade em todos esses níveis e nas diversas modalidades de ensino são tarefas prioritárias, conforme o Plano Nacional em Direitos Humanos.

Vale destacar também, que o Plano Nacional de Educação em Direitos Humanos (PNEDH) é um passo importante na efetivação e implementação do direito à educação. Teve sua primeira versão em 2003, consolidou-se em 2006 e foi uma grande conquista histórica em relação ao art. 26, Da Declaração de 1948 (GIOVANNETTI; FISHMANN, 2009, p. 217) - o qual trata do direito de instrução. 
Este compreende os Direitos Humanos em seu sentido amplo, analisa a dignidade da pessoa humana e compreende o direito à saúde, à alimentação, ao lazer. Ainda, o Plano está apoiado em documentos internacionais e nacionais, demarcando a inserção do Estado brasileiro na história da afirmação dos direitos humanos e na Década da Educação em Direitos Humanos, prevista no Programa Mundial de Educação em Direitos Humanos (PMEDH) e seu Plano de Ação (PLANO NACIONAL, p. 21-23).

\subsubsection{Lei de Diretrizes e Bases da Educação}

Ressalte-se a importância nos estudos do Direito à educação contextualizar a Lei n. 9394/96 (Lei de Diretrizes e Bases da Educação Nacional), em que pese seus limites, possibilita também, avanços e seu art. 1 destaca que os processos formativos são responsabilidade:

\footnotetext{
Art. $1^{\circ} \mathrm{A}$ educação abrange os processos formativos que se desenvolvem na vida familiar, na convivência humana, no trabalho, nas instituições de ensino e pesquisa, nos movimentos sociais e organizações da sociedade civil e nas manifestações culturais.

$\S 1^{\circ}$ Esta Lei disciplina a educação escolar, que se desenvolve, predominantemente, por meio do ensino, em instituições próprias.

$\S 2^{\circ} \mathrm{A}$ educação escolar deverá vincular-se ao mundo do trabalho e à prática social.
}

A LDB veio com o intuito de disciplinar a educação e postular um novo molde, uma nova divisão. Dentre as inovações e a democratização educacional, pontua-se (PILLETI; PILLETI, 2016, p. 226-227):

- Gestão democrática - do ensino público na educação básica, tendo a participação dos profissionais de educação na elaboração do projeto da escola, e da comunidade na escola (art.14);

- Autonomia- na gestão financeira, pedagógica e administrativa, conforme o art.15;

- Nova composição da escola: educação básica- formada pela educação infantil/pré escola, ensino fundamental (antigo $1^{\circ}$ grau) e ensino médico (antigo $2^{\circ}$ grau) e ensino superior, conforme art. 21;

- Oportunidade para jovens e adultos que não estudaram na idade regular (EJAeducação de jovens e adultos), assegurado pelo art. 37, passam a ter possibilidade de inserção no sistema de ensino, gratuitamente; 
- EDUCAÇÃO profissional (art. 40 da LBD desenvolvida com articulação com o ensino regular; educação especial art. 58, onde os educandos portadores de necessidades especiais estudam na rede regular de ensino gratuita), educação especial, a possibilidade de reclassificar o aluno;

- A busca da valorização do trabalho do professor.

Assim, destaca-se que o país conta com 186,1 mil escolas de educação básica; sendo que a maior rede está sob a responsabilidade dos municípios, concentrando cerca de $2 / 3$ das escolas (114,7mil). A participação das escolas da rede privada passou de 21,1\% em 2015 para 21,5\% em 2016. Notas estatísticas - Censo Escolar 2016.

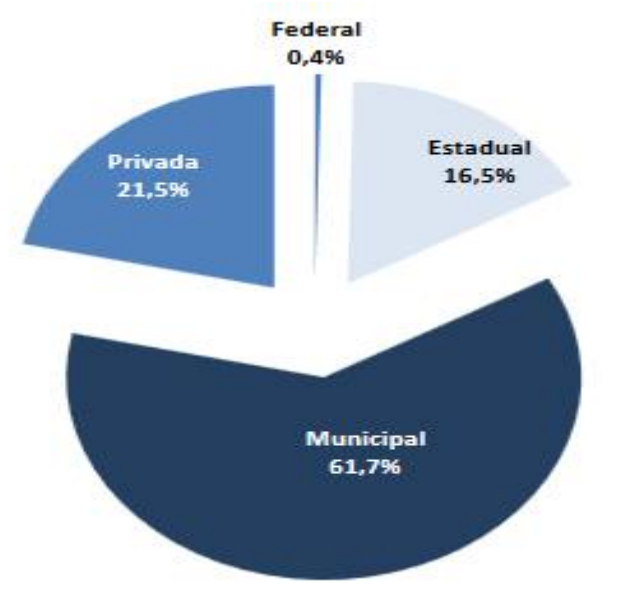

Gráfico 1. Percentual de escolas de educação básica por dependência administrativa - Brasil 2016 Fonte: INEP

De acordo com o gráfico acima, percebe-se a realidade do país, em consonância com a LDB que a Educação básica do país é de responsabilidade do município (61,7\%). Cabe a união, apenas $0,4 \%$ do ensino básico. As instituições privadas contribuem com $21,5 \%$ e o estado com 16,5\%. Vale destacar que em 2019, no senso referente ao ano de 2018, a educação básica de responsabilidade do município é de 47,7\%, cabendo ao Estado 32,9\%, 0,8\% à esfera federal e às instituições privadas $18,6 \%{ }^{9}$.

Ainda importante citar- de forma conclusiva - ProUni e a Lei de Cotas no ensino superior para indígenas e negros, sendo que a Lei de Cotas reserva no mínimo 50\% das vagas das instituições federais de ensino superior e técnico para estudantes de escolas públicas, que são preenchidas por candidatos autodeclarados pretos, pardos e indígenas. Dessa forma, a

\footnotetext{
${ }^{9}$ INEP. Instituto Nacional de Estudos e Pesquisa Educacional Anísio Teixeira, 2019. Resumo técnico censo da educação básica 2018. Disponível em: <http://download.inep.gov.br/educacao_basica/censo_escolar/resumos_ tecnicos/resumo_tecnico_censo_educacao_basica_2018.pdf>. Brasília, 2019.
} 
proposta do Direito à Educação para minorias vem para facilitar o acesso e permanência nos diversos níveis de ensino. Assim, como esse é um tema polêmico- com correntes doutrinárias a favor e contra - ficará para ser discutida em uma pesquisa própria sobre políticas públicas.

\section{CONCLUSÃO}

Ao promover o presente estudo, importante se faz lembrar que a Constituição Federal de 1988 está em total harmonia com a Declaração Universal dos Direitos Humanos de 1948no que se refere aos Direitos Humanos e no Direito à Educação.

Percebe-se que o tema é de suma importância, com decisões pacificadas acerca do tema, porém, para pensar verdadeiramente uma outra realidade educacional, é necessário levar em consideração a ordem econômica, pedagógica, cultural e social. O direito à educação ainda tem um caminho longo e complexo para seguir até atingir um patamar louvável. A sala de aula é o local onde se percebe os maiores problemas mas também, o lugar de esperança e possibilidades infinitas. A educação faz parte do direito indispensável para o desenvolvimento.

A educação possui Legislação específica, bem como documentação internacional que reconhece esses Direitos Humanos à educação, contudo, além de questões políticas, econômicas do país, a falta de aplicabilidade das leis e das sanções- que são praticamente inexistentes- impedem uma alavancada considerável da educação. Devem ser consideradas de forma diferente das que já foram apresentadas, que as diferenças de cor, raça, credo, culturas, discriminação de uma forma geral, criam realidades e oportunidades diferentes; negros e índios possuem diferenças no que tange ao acesso às escolas, porém, as necessidades são as mesmas dos demais indivíduos.

No estudo de Direitos Humanos, para a construção de uma realidade diferente a única solução é o real investimento na educação, entretanto, no Brasil essa mentalidade ainda não foi adquirida pela sociedade. As pessoas não tem noção de que o fim dos problemas e contradições sociais estão proporcionalmente ligadas à admissão de pessoas à escola, ou sejam quanto mais crianças e pessoas na escola, menos diversidades, menos marginalidade e maior crescimento econômico e melhor será a construção intelectual, ética e moral dos indivíduos.

Impossível não voltar ao primeiro pensamento citado do Dr. Gikovate, o qual será com certeza a comprovação de toda a pesquisa- onde ele expõe que nada é mais importante que a educação. 
Recriar, reinventar os Direitos Humanos é o novo desafio para a sociedade atual.

\section{REFERÊNCIAS}

AIDAR, Lucas. Direito à educação no STF: conceitos, limites e possibilidades. Monografia apresentada à Escola de Formação da Sociedade Brasileira de Direito Público - SBDP, sob a orientação da Professora Patrícia Pessoa Valente. SÃO PAULO, 2011. Acesso em: 24.mai.2017. Disponível em: <http://www.sbdp.org.br/ arquivos/monografia/185_Lucas\%20 Aidar.pdf> e <http://pne.mec.gov.br/>. Acesso em: 02.out.2018.

BUARQUE, Cristovam. Como fazer! A revolução pela educação. Ações de Governo 20072010 para construir um Brasil ate 2022. Brasília, 2006.

CENSO ESCOLAR DA EDUCAÇÃO BÁSICA 2016/2017. Notas estatísticas Brasília/ fevereiro de 2017. Disponível em: <http://download.inep.gov.br/educacao_basica/censo_escolar/notas_estatisticas/2017/notas_st eatisticas_censo_escolar_da_educacao_basica_2016.pdf > Acesso em: 11.dez.2018.

COMPARATO, Fábio Konder. A afirmação histórica dos direitos humanos. 10. ed. São Paulo: Saraiva, 2015.

GIKOVATE, Flávio. A arte de educar. 2. ed. São Paulo: MG editores, 2002.

GIOVANNETTI, Andrea. 60 anos da Declaração Universal dos Direitos Humanos: conquistas do Brasil. [org.] Andrea Giovannetti - Brasília: Fundação Alexandre de Gusmão, 2009.

INEP. Instituto Nacional de Estudos e Pesquisa Educacional Anísio Teixeira, 2019. Resumo técnico censo da educação básica 2018. Disponível em: <http://download.inep.gov.br/educacao_basica/censo_escolar/resumos_tecnicos/resumo_tecni co_censo_educacao_basica_2018.pdf >. Brasília, 2019.

LIMA, Jayme Benevuto Junior. Os direitos humanos econômicos, sociais e culturais. Rio de Janeiro-São Paulo: Renovar, 2001.

MAZZUOLI, Valério de Oliveira. Curso de direitos humanos. 3. ed. rev.atual.e ampl.- Rio de Janeiro: Forense, São Paulo: Método, 2016.

MEDEIROS, Noé de. Os direitos humanos e os efeitos da globalização. Barueri-SP: Minha Editora, 2011. 
MONACO, Gustavo Ferraz de Campos. A proteção da criança no cenário internacional. Belo Horizonte: DelRey, 2008.

ONUBR. UNESCO - Organização das Nações Unidas para a Educação, a Ciência e a Cultura. Disponível em: <https://nacoesunidas.org/agencia/unesco/> Acesso em: 01.abr.2019.

PES, João Hélio Ferreira [coord.]. Direitos humanos: crianças e adolescentes. Joao Hélio Ferreira Pes [coord.] Curitiba: Juruá, 2010.

PILATTI, Claudino; PILATTI, Nelson. História da educação: de confúcio a Paulo Freire. São Paulo: Contexto, 2016.

PIOVESAN, Flávia [coord.]. Direitos humanos: fundamento, proteção e implementação. Flávia Piovesan, Daniela Ikawa [coords.]. Curitiba: Juruá, 2010.

PLANO Nacional de Educação em Direitos Humanos / Comitê Nacional de Educação em Direitos Humanos. Brasília: Secretaria Especial dos Direitos Humanos, Ministério da Educação, Ministério da Justiça, UNESCO, 2007.

SUPREMO TRIBUnAl FEDERAL. A Constituição e o Supremo. Disponível em: $<$ http://www.stf.jus.br/ portal/constituicao/artigobd.asp?item $=\% 201888$ >. Acesso em: 20.fev.2019.

TAVARES, RAQUEL O que são os direitos humanos? Disponível em: <http://direitos humanos.gddc.pt/IPAG1.htm>. Acesso em: 02.out.2018.

WEIS, Carlos. Direitos humanos contemporâneos. 3. ed. revista e aumentada. São Paulo: Malheiros Editores, 2012.

INEP. Plano Nacional de educação em direitos humanos. Disponível em: $<$ http://portal.mec.gov.br/index.php?option=com_docman\&view=download\&alias=2191plano-nacional-pdf\&category_slug=dezembro-2009-pdf\&Itemid=30192.> Acesso em: 01.out.2018.

SACAVINO, Susana. Texto apresentado no XIII Encontro Nacional de Didática e Pratica de Ensino, promovido pelo Programa de Pós-Graduação em Educação na Universidade Feral de Pernambuco. Realizado em Recife, em 2006. Disponível em: $<$ http://www.dhnet.org.br/direitos/militantes/susanasacavino/sacavino_dh_educ_br_conquista. pdf $>$. Acesso em: 16.out.2018. 